\title{
A technical-economic analysis of telemetry as a monitoring tool for crop protection in viticulture
}

\author{
Daniele Sarri, Stefania Lombardo, Andrea Pagliai, Luca Zammarchi, Riccardo Lisci, Marco Vieri \\ Department of Agriculture, Food, Environment and Forestry, University of Florence, Florence, Italy
}

\begin{abstract}
Based on the European Community framework directive 2009/128/EC that is devoted to the sustainable use of pesticides, farmers' sensitivity and their administrative fulfillments are growing in recent years. Great attention is directed towards remote data acquisition by smartphone, satellites, drones. An available technological tool to accomplish this in the scenario of precision viticulture technologies is telemetry. This study aimed to evaluate the usefulness of the data acquired with a telemetry system used when applying crop protection products in a winemaking farm for management optimization. Results showed an incorrect operative operation rate for $9.53 \%$ of the total kilometers worked during the spraying phase with a variable cost for fuel and pesticides ranging between $0.01 € \mathrm{~m}^{-1}$ and $0.03 € \mathrm{~m}^{-1}$.
\end{abstract}

\section{Introduction}

Application of crop protection products in viticulture, and more generally in specialized crops, is the phase of highest frequency and logistical complexity and has a direct impact on the

Correspondence: Daniele Sarri, Department of Agriculture, Food, Environment and Forestry System, University of Florence, p.le delle Cascine 15, Firenze 50144, Italy.

E-mail: daniele.sarri@unifi.it

Key words: Spraying operative errors; monitoring; management; pesticide, cost.

Acknowledgements: the authors wish to thank Dr Gionata Pulignani and Dr Formicola Daniele and all the staff of the Azienda Agricola Mazzei (Castellina in Chianti, Fonterutoli, Siena, Italy) for host the field experiments and the technical support.

Funding: this work was supported by public founding provided by Tuscany Region through the VELTHA project PIF 43/2015.

Received for publication: 4 November 2019.

Accepted for publication: 20 January 2020.

${ }^{C}$ Copyright: the Author(s), 2020

Licensee PAGEPress, Italy

Journal of Agricultural Engineering 2020; LI:1029

doi:10.4081/jae.2020.1029

This article is distributed under the terms of the Creative Commons Attribution Noncommercial License (by-nc 4.0) which permits any noncommercial use, distribution, and reproduction in any medium, provided the original author(s) and source are credited. success of the entire production process. The scarce availability of companies which provide remote-control technology and data logging in the agriculture sector limits the possibility of technicaleconomic optimization of this strategic phase. In vineyard crop protection, it is possible to highlight a dualism: i) intense work and investment made by the pesticide producer to identify new and more sustainable molecules; and ii) the slow technological improvement of smart sprayers and devices for acquiring data during the application stages which still remain limited. At the same time, telecommunication systems are growing and spreading quickly and can contribute to the implementation of precision monitoring and field data mining (Albedo et al., 2016; Oksanen et al., 2016). Tseng et al. (2006), one of the pioneers of telemetry systems in the agricultural sector, state that this type of technology can provide a wide range of advantages to enhance agricultural production, optimise returns, reduce risks for crops, and minimise the environmental impact.

Telemetry has been successfully introduced for various agricultural operations, e.g., the monitoring of harvesting olive yards (Castillo-Ruiz et al., 2015). Gil et al. (2014) implemented a telemetry network sensor to assess the drift produced during the spraying operation in viticulture. Sarri et al., (2017) developed a telemetry system based on general packet radio service (GPRS) global system for mobile communication (GSM) for the monitoring of crop protection stages. This telemetry provides operative parameters such as sprayer status, maps of pathways, forward speed, applied volume, and applied rate through a combination of WebGIS platforms and hardware. Similarly, the Sika-PICORE monitoring system combines technologies Wifi, Bluetooth, GPRS or GSM for the local transfer between a smartphone and remote of the operating parameters of sprayers (Sika- PICORE, 2019). Other solutions provide local data acquisition and the generation of reports such as the system Agrotrack, which stores data such as application rate, forward speed, pathways in an SD memory but without the transmission to a web server (Reyes et al., 2012). In this framework, this study aimed to evaluate the technical and economic usefulness of the data acquired with a telemetry system to assess the magnitude of operative errors compared to the ideal implementation in economic and efficiency terms. The economic aspects were analysed by fixed and variable costs related to the yard consumption (tractor coupled to air-blast sprayer) according to the ASABE Standard EP496.3. A particular focus was made on fuel, pesticides and water consumption, which are the three elements that cause the most significant impact of agriculture on the environment. Finally, thanks to the telemetry system, it was possible to monitor the efficiency rates of each single working day during the crop protection stages. 


\section{Materials and methods}

The research site was located in Tuscany, in the central part of Italy, near the city of Siena, on a winery farm $(43.435641 \mathrm{~N}$, 11.302821 E). Vineyards were in the Val d'Elsa hills, in the center of the Chianti Classico production area. The total area of the vineyard was 117 ha. There were 73 vineyard production units, divided into a total of 120 plots, $90 \%$ of which with a row spacing of 2.0 $\mathrm{m}$. The study analysed data related to crop protection stage performed in the 2017 season. A total of 13 treatments, applied between May 7 and September 14, were monitored. The application rate used for the treatments varied according to the seasonal average phenological stage: the first phase was from budding to distension of the first three to four leaves, average LAI 0.5 and was sprayed with $150 \mathrm{~L} \mathrm{ha}^{-1}\left(\mathrm{AR}_{150}\right)$; the next phase was up to LAI 0.9 and was sprayed with $200 \mathrm{~L} \mathrm{ha}^{-1}\left(\mathrm{AR}_{200}\right)$, while at the maximum canopy growth LAI 1.3 was sprayed with $250 \mathrm{~L} \mathrm{ha}^{-1}\left(\mathrm{AR}_{250}\right)$.

\section{Instrumentation - telemetry module}

The hardware set up consists of an OVIDIA MTX $65+\mathrm{G} \mathrm{V} 3$ differential global positioning system receiver (DGPS) plus GSM and GPRS radio terminal (Figure 1). The GPRS modem had its intrinsic transmission control protocol (TCP) and internet protocol (IP) stack that allowed the data packet to transfer every $10 \mathrm{~s}$. Two external receivers for the DGPS and GSM were installed on the roof of the tractor. The DGPS receiver had a wide area augmentation system (WAAS) and used the European Geostationary Navigation Overlay Service (EGNOS) for differential correction. The accuracy was $1 \mathrm{~m}$ in the horizontal plane for circular error probability (CEP) and $1 \mathrm{~m}$ in the horizontal and vertical plane for the spherical error probability (SEP).

\section{Instrumentation - improved system scheme}

The MTX $65+$ G V3 has its own SIM card reader and standard connector interfaces. The connector interface had six connecting pins including two analogue inputs, one pulse counter, and two for power supply. To monitor spraying operations, the following connections were made: pin 1 was connected to the tractor ON/OFF key, pin 2 and pin 4 were connected to the right and left side of the spray-head, pin 5 was connected to $12 \mathrm{~V}$ DC power supply, and pin 6 was connected to the negative terminal of the tractor battery. The connection on pin 1 allowed monitoring the status of the tractor. After turning the tractor ON/OFF key or after the activation of the ON/OFF line, the system would send attention commands (AT) to the server and initiate or end up the section. A real time clock (RTC) provided accurate timekeeping and enabled time stamping of messages. When the tractor key was turned OFF, the MTX $65+$ G V3 terminal was logged off from the network. At the same time, the software would lead the module into a secure state and save data before disconnecting the power supply. This mode was referred to as power-down mode. In this mode, only the RTC stayed active and battery discharging was limited. The MTX $65+$ G V3 configuration was done by setting a forwarding threshold . This allowed the system to recognize a change in condition from parking or activity. Given the limited accuracy of the GPS system, it was set to be $0.6 \mathrm{~km} \mathrm{~h}^{-1}$ because smaller values introduced noise in the discrimination process. The monitoring of the sprayer was carried out by connecting the analogue inputs to the two drive switches linked to the solenoid valves of the right and left section of the sprayer-head. This configuration made it possible to evaluate the individual activation and switch-off phases. The PTO drive was not considered as it was continuously active for machine operation and does not represent a spraying error risk, as the failure to activate was clearly audible. Hardware settings and GPRS data
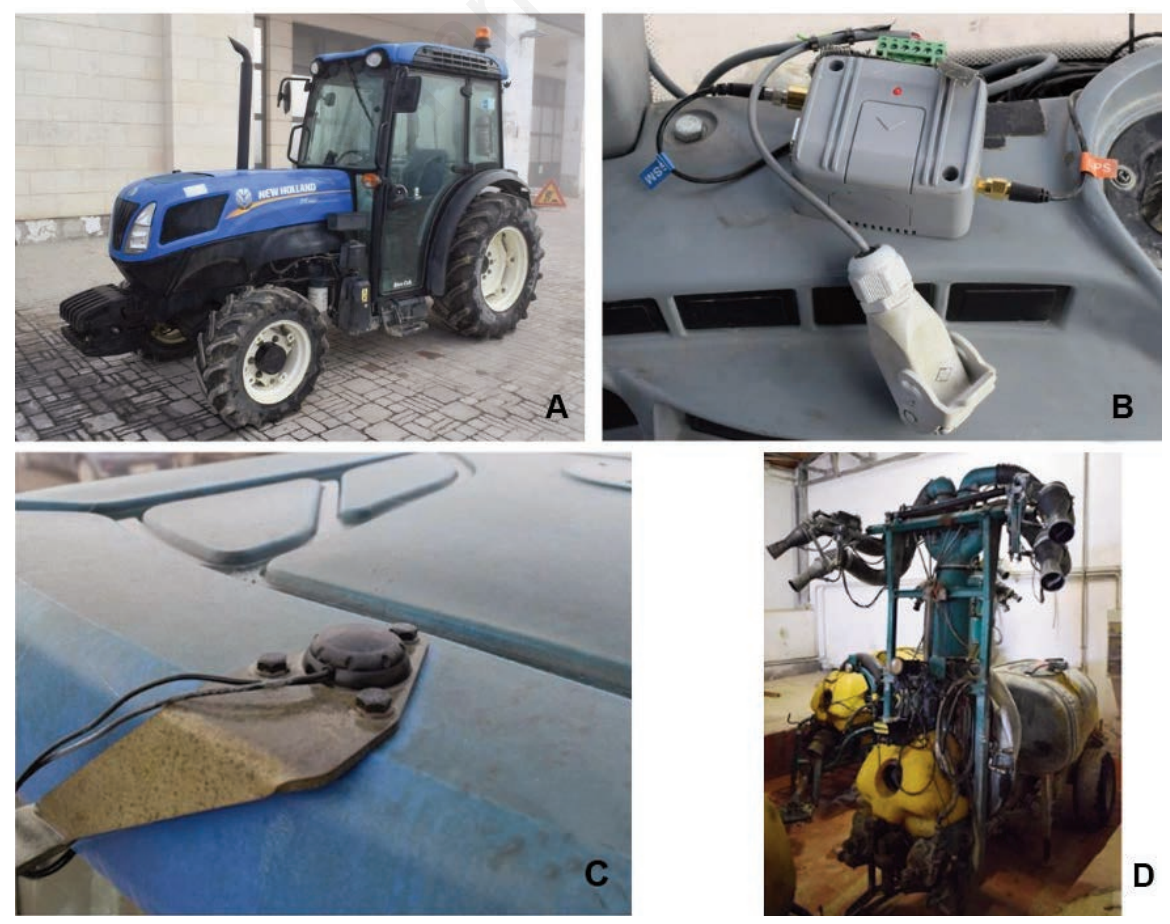

Figure 1. The MTX $65+$ G V3 telemetry module (B) installed onboard of the tractor (A) coupled with a pneumatic sprayer (D). In panel $\mathrm{C}$, the connector that links the telemetry module to the on/off switches of the sprayer. In (D) GPS mounted on the roof of the tractor. 
packet management were available through the WebGIS Agroplanning platform. Agroplanning consisted of two main elements: a cloud server and a user terminal. A graphical user interface (GUI) allowed for instantaneous interaction and settings for the client. The platform was divided into eight main sessions: i) dashboard with the sub-sessions of activities performed in the last 30 days, minimap which showed the last parked position of the vehicle, and notifications window for the communication from server administrator; ii) Map with a set of base layers of terrain map, routes, and satellite images; iii) Vehicles where all data related to the machine were stored and where it was possible to edit the features; iv) Farms which was a simplified GIS where it was possible to edit and upload each single farm plot and perform individual analysis; and v) Report where the algorithms and equations to calculate and query the system for each variable of interest (sensors, vehicle status, speed, heading) were found. The other three sessions were related to upgrading solutions of the platform, communication with the site manager, and client assistance, and were not used for the study. Agroplanning processed all the data received from the MTX $65+\mathrm{G} \mathrm{V} 3$, distinguishing four main activities: i) Idle, or pause state, refers to conditions in which the vehicle was stationary or was recording speeds of less than $0.6 \mathrm{~km} \mathrm{~h}^{-1}$; ii) Towed, refers to distances travelled with the engine OFF, i.e., when the vehicle is towed or hauled on a trailer. In this case, the device remained active using the on-board battery it was equipped with; iii) Transport, relative to moving equipment to other locations, was recorded when speeds exceeded $0.6 \mathrm{~km} \mathrm{~h}^{-1}$ and with left and right sides of the spray-headswitched off; iv) Worked, refers to the work operations (in this study, only crop protection applications), and was identified when speeds were higher than $0.6 \mathrm{~km} \mathrm{~h}^{-1}$ and with at least one of the sides of the spray-head working. Available data were: Date (mm/dd/yyyy), Position (Latitude, Longitude - WGS 84), Height (meter above the sea), Speed $\left(\mathrm{km} \mathrm{h}^{-1}\right)$,
Heading (compass direction in degree), Fix, Coverage (\% GSM network), RPM (revolutions per minute $\mathrm{n}^{\circ}$ ), Analog1 (ON/OFF), Analog2 (ON/OFF), Engine Status (1 ON - 0 OFF), Battery (level $\%)$, Total Hours (hours.minutes), and Total Km (nnnn.nn). Data used for the technical analysis were time, latitude, longitude, speed of the sprayer, and functioning side of the spray-head (left or right). The values acquired through the telemetry system, in the form of machinery transit pathways, were analyzed and compared with the correct lines of transit in the vineyard to assess the differences and identify errors

\section{Instrumentation - spraying vineyard}

The MTX $65+$ G V3 was installed onboard of a tractor(New Holland T4/95N), which was used for the entire season for the crop protection applications. A pair of cables were connected to the drive switches on the left and right side of the sprayer. This installation allowed monitoring of the activations and deactivations performed by the operator. The average forward speed was fixed at 5 $\mathrm{Km} \mathrm{h}^{-1}$. Treatments were performed by an articulated pneumatic sprayer (Link55, Cima ${ }^{\circledR}$ ) with a 1000 L tank and eight spray-head, four on each side (Cima, 2019), which simultaneously sprayed four sides of the inter-rows of a vineyard. Logistically, spraying was done in alternate vines' rows. In addition, each plot was sprayed around the entire external boundary after the vine interrows were sprayed.

\section{Operative assessment}

To assess the potential of the telemetry system, operational error cases were identified. These were compared with respect to the correct execution, considering the pathways and sprayer activation errors. Four main recurring operational errors were identified (Figure 2): i) repeated inter-rows (RI) - vineyard sprayed the same inter-row
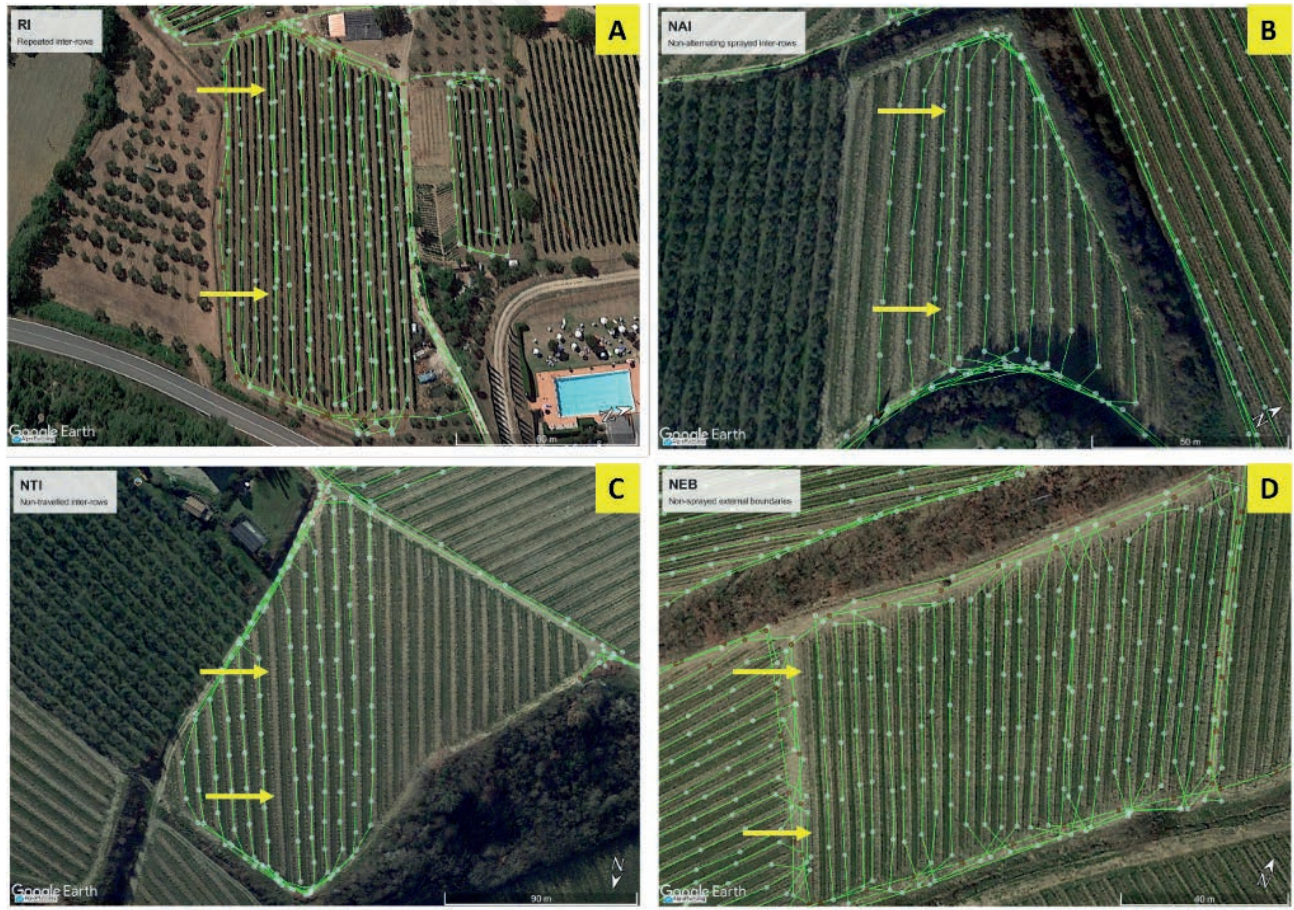

Figure 2. Operational pathways errors identified during the spraying stage: A) repeated inter-rows; B) non-alternating sprayed interrows; C) non-travelled inter-rows; $D$ ) non-sprayed external boundaries. 
twice; ii) non-alternating sprayed inter-rows (NAI) - incorrectly travelled with the sprayer in operation; the correct inter-row was not travelled, and therefore the execution of the treatment was not carried out based on the right course of alternating inter-rows; iii) non-travelled inter-rows (NTI) - inter-rows that the operator should have travelled with the sprayer activated to perform the treatment properly; iv) nonsprayed external boundaries (NEB) - untreated canopy espalier of the external rows of the vineyard where the operator did not travel. The assessment of analytical errors was determined based on the meters of inter-row canopy espalier treated in excess or shortfall by the vineyard, also distinguishing between the conditions in which the sprayer had to be activated or not. The Keyhole Markup Language (KML) files of each working session, which allow machine data rendering on the WebGIS Google Earth Pro platform (Google Earth, 2019), were downloaded. Moreover, for each treatment, the related database in comma separated values (.csv) was used to perform an analytical evaluation through spreadsheet software (Microsoft, 2013). The georeferenced position data were analysed with the geographical information system (GIS) ESRI ArcMap 10.3 software (ESRI, 2013). This software was used to remove all GNSS position outliers to correct .csv data.

The total error path (TEP), expressed in kilometres, was measured by summing the four types of errors described above (Eq. 1).

$T E P=R I+N A I+N T I+N E B$

\section{Methodology for the cost analysis}

\section{Spraying equipment costs}

ASABE Standard EP496.3 methodology was used to assess the spraying equipment costs. The cost was determined by calculating the Total hourly cost. Two main categories of costs were considered: variable costs and fixed costs. The former were costs that are activated together with the production process, and they include fuel and lubricant consumption costs (proportional to the power used), repair and maintenance costs, and the costs associated with driver's working hours (labour costs). The fixed ones are: sundry expenses (taxes, housing and insurance), annual amortization rate and yearly interest.

\section{Fuel consumption}

Fuel consumption data were acquired by breakdown of consumption during the spraying and the transfer phases. These were quantified in six working stages, with variable orographic conditions ranging from flat land to hill with $15 \%$ of slope, by measuring the remaining fuel litres manually inside the tank by difference to the known initial volume of $25 \mathrm{~L}$. The working stages were monitored for a minimum of 30 minutes. Then, the consumptions were attributed to the spraying stages paths obtained from the Agroplanning platform. Then the specific fuel consumption of operational errors RI, NAI, NTI, and NEB was calculated as follows (Eq. 2):

$$
F C_{T E P}=\left[\left(\frac{R I ; N A I ; N T I ; N E B}{v}\right) \times F C\right] \times € L^{-1}
$$

where $\mathrm{FC}_{\text {TEP }}$ is the fuel cost of total error path $(€), v$ is the mean forward speed $\left(\mathrm{km} \mathrm{h}^{-1}\right), \mathrm{F}_{\mathrm{c}}$ is the mean fuel consumption in the spraying stage $\left(\mathrm{L} \mathrm{h}^{-1}\right)$, and $€ \mathrm{~L}^{-1}$ is the national fuel price set at $0.85 € \mathrm{~L}^{-1}$ (CCIAA Siena, 2018). The values were considered as the amount of fuel in excess $(+)$ and lost (-) consumption compared to the correct path.

\section{Pesticide consumption}

The pesticide costs of total error path (PC $\mathrm{PEP}_{\mathrm{TEP}} €$ ) were evaluated based on the unitary costs provided by the farm at the three levels of application rates (Eq. 3). The active ingredients used belong to the category of organic fungicides based on copper and sulfur, and to the systemic fungicides active against the major fungal diseases, such as Plasmopara Viticola (Berk \& Curt.) Berl. \& de Toni, Uncinula Necator (Schw.) Burr., Guignardia Bidwelli (Ellis) Viala \& Ravaz) and Botrytis Cinerea Pers. ex Fr. A three step process calculated the cost. Firstly, the duration of operational error was calculated by dividing the errors paths to the average forward speed recorded by Agroplanning. Secondly, each duration (min) was multiplied to the sprayer flow rate $\left(\mathrm{L} \mathrm{min}^{-1}\right)$. This provides the amount of spraying in excess $(+)$ and lost $(-)$ compared to the correct path. Then these data were multiplied by the average costs of treatments for the three levels of AR. Finally, the PC TEP was calculated by summing the average costs of treatments for the three level of AR (Eq.3).

$$
\begin{aligned}
& P C_{T E P}=\left[\left(\left(Q_{150} \times\left(\frac{R I ; N A I ; N T I ; N E B}{v}\right) \times C_{m 150}\right)\right)+\right. \\
& \left(\left(Q_{200} \times\left(\frac{R I ; N A I ; N T I ; N E B}{v}\right) \times C_{m 200}\right)\right)+ \\
& \left.\left(\left(Q_{250} \times\left(\frac{R I ; N A I ; N T I ; N E B}{v}\right) \times C_{m 150}\right)\right)\right]
\end{aligned}
$$

Q150; 200; 250 are the three levels of flow rate of the sprayer (L $\left.\min ^{-1}\right), v$ is the mean forward speed $\left(\mathrm{km} \mathrm{h}^{-1}\right), \mathrm{C}_{\mathrm{m} 150 ; \mathrm{m} 200 ; \mathrm{m} 250 \text { are }}$ the average costs of pesticide mixture $\left(€ \mathrm{~L}^{-1}\right)$. For the $\mathrm{AR}_{150}$ level the average cost $\left(\mathrm{C}_{\mathrm{m} 150}\right)$ is $49.56 €$, for $\mathrm{AR}_{200}\left(\mathrm{C}_{\mathrm{m} 200}\right)$ is $103.12 €$ and for $A_{250}\left(C_{m 250}\right)$ is $72.93 €$. The winery farm provided these costs and therefore they were the real costs that the farm incurred for the purchase of pesticides.

\section{Water consumption}

For water consumption we mean the water used to prepare the phytoiatric mixture. The water costs of total error path (WC $\mathrm{WEP}_{-} €$ ) were evaluated based on the same pattern of PC TEP. The error paths were divided to the average speed, recorded by Agroplanning, to find the duration of operational error. Then, each duration (min) was multiplied to the three levels of sprayer flow rate $(\mathrm{L} \mathrm{min}-1)$. Finally, the sum of these data was multiplied by the unit water cost (Eq. 4).

$$
\begin{aligned}
& W C_{T E P}=\left[\left(Q_{150} \times\left(\frac{R I ; N A I ; N T I ; N E B}{v}\right)+\right.\right. \\
& Q_{200} \times\left(\frac{R I ; N A I ; N T I ; N E B}{v}\right)+ \\
& \left.\left.Q_{250} \times\left(\frac{R I ; N A I ; N T I ; N E B}{v}\right)\right) \times € L^{-1}\right]
\end{aligned}
$$

Q150; 200; 250 are the three levels of flow rate of the sprayer (L $\left.\min ^{-1}\right), v$ is the mean forward speed $\left(\mathrm{km} \mathrm{h}^{-1}\right), € \mathrm{~L}^{-1}$ is the regional water price set at $0.003 € \mathrm{~L}^{-1}\left(2.96 € \mathrm{~m}^{-3}\right)$ (Acquedotto del Fiora, 2019).

\section{Sprayer equipment efficiency analysis}

The telemetry system installed on the tractor allowed to record the working time (i.e. when sprayer equipment was spraying vine- 
yards), the time of transport (i.e. when sprayer equipment was moving between vineyards) and of pause idle (i.e., when the tractor was stationary, for example to recharge the tank of the sprayer). With these data it's possible to know the sprayer equipment efficiency rate. It was calculated by dividing the working time by the sum of working time, transport and pause (Eq. 5).

$$
E F F_{S E}=\frac{t_{w}}{t_{w}+t_{t}+t_{p}}
$$

\section{Statistical analysis}

The length of pathways errors in relation to the AR, which were normally distributed ( $p$-value of the Shapiro-Wilk test $>0.05$ ) were modelled by a two way ANOVA using the R statistical software (R Core Team, 2013). The main effects of the two treatments (Application rate, Error pathways) and their interaction are all of equal interest. Test for significant treatment effects for factor AR, Error pathways and significant interaction effects were performed with a two-way ANOVA. All model specification tests were conducted, i.e., verifications that the mean of the errors was not significantly different from zero using the Student's $t$-test, that the errors were normally distributed using the Shapiro-Wilk's normality test, homoscedasticity verification using the Levene's Test and Breusch-Pagan's test, and the serial correlation using the DurbinWatson's test. A multiple pairwise-comparison between the means of Error Pathways with Tukey's HSD test was performed. From the model outputs we have been set that the test does not reject the null hypothesis with equal variances at a $5 \%$ significance level.

\section{Results}

Test for significant treatment effects for factor AR and Error pathways showed no difference in the means of factors. The twoway analysis highlighted that there was no statistically significant interaction between the effects of $\mathrm{AR}$ and errors pathways $(\mathrm{F}=2$. 25, $\mathrm{P}=0.09$ ). Tukey's HSD post hoc tests were carried out. For all the error pathways there is no evidence to suggest differences (P values range from 0.47 to 0.99 ). Normality checks and Levene's test were carried out. Therefore, we can assume the homogeneity of variances in the different Error pathways (RI - $\mathrm{F}=0.35 \mathrm{p}$ values $=0.71$; NAI $-\mathrm{F}=0.39 \mathrm{P}=0.67$; NTI $-\mathrm{F}=0.41 \mathrm{P}=0.67$; NEB $-\mathrm{F}=0.55$ $\mathrm{P}=0.59$ ). Table 1 lists the economic parameters used for applying the ASABE EP496.3 methodology. The purchase price of the tractor was estimated in $50,000 €$ according to the price list of New Holland, and for the air-blast sprayer in $12,000 €$ according to the

Table 1. Economic parameters used when applying the ASABE Standard EP496.3 for equipment cost analysis.

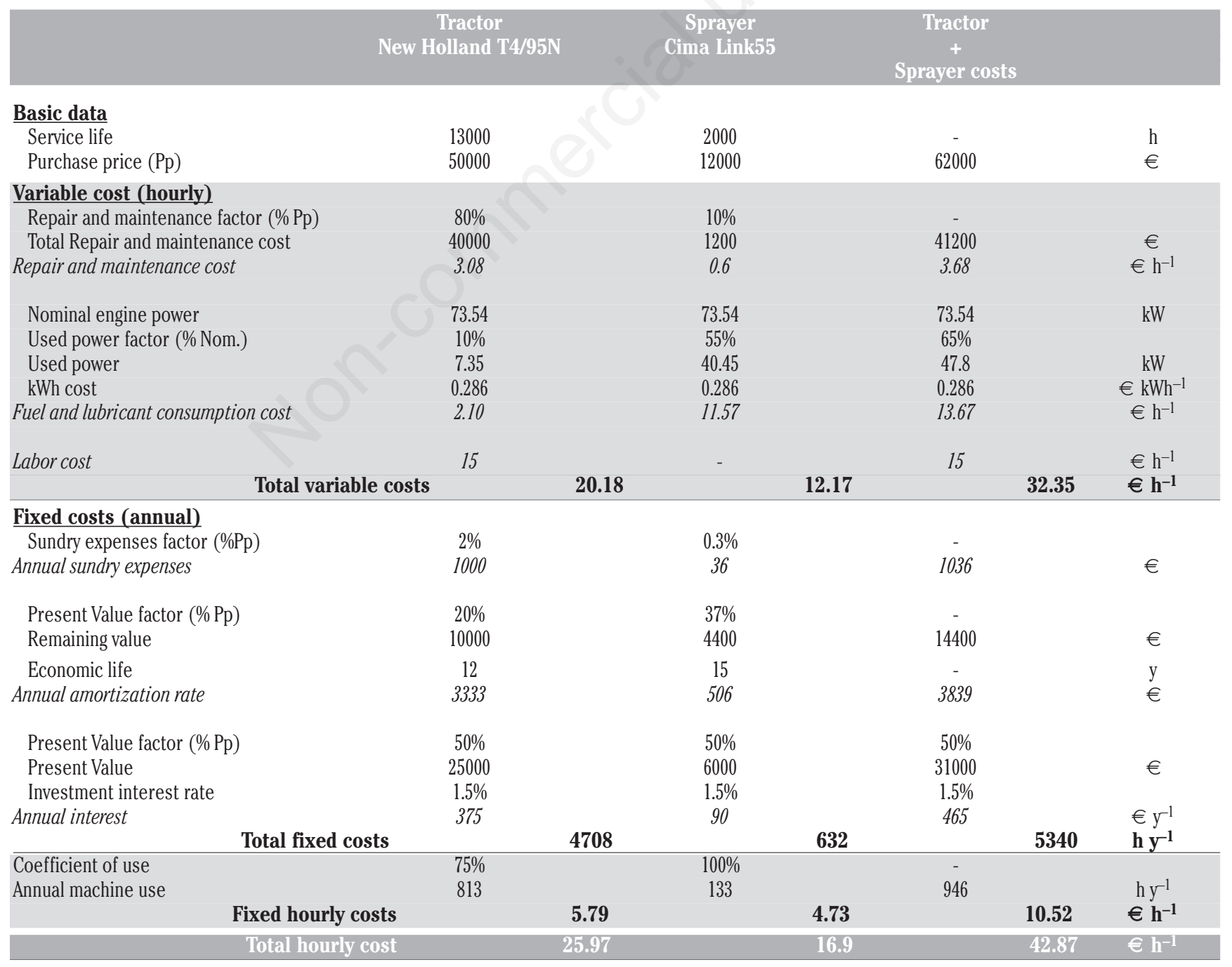


price list of Cima Spa (New Holland Agriculture, 2019; Cima, 2019). The cost analysis was divided into two main categories: variable and fixed costs. Each category referred both to single equipment units (tractor or air-blast sprayer) and to coupled equipment unit (tractor and air-blast sprayer). Variable costs were: i) repair and maintenance cost; ii) fuel and lubricant cost; iii) and labor cost $\left(€ \mathrm{~h}^{-1}\right)$. The repair and maintenance costs were calculated using the factors of $80 \%$ on the purchase price for tractor and to $10 \%$ for air-blast sprayer. Then, these values were divided for the service life to find the repair and maintenance hourly cost $\left(€ \mathrm{~h}^{-1}\right)$. The fuel and lubricant costs were calculated on the used power for each equipment through the engine power $(\mathrm{kW})$ of the tractor and the used power factor, i.e. $10 \%$ for the tractor and $55 \%$ for air-blast sprayer. Thus the used power found was multiplied for the fuel and lubricant cost referred to $\mathrm{kWh}$ provided by the manufacturers. Finally, labour cost was set at $15\left(€ \mathrm{~h}^{-1}\right)$ considering the salary of a not specialized worker. Instead, in fixed costs there were: i) yearly sundry expenses; ii) yearly amortization rate; iii) yearly interest. The yearly sundry expenses were calculated applying a factor of $2 \%$ for tractor and $0.3 \%$ for the sprayer on the purchase price. The yearly amortization rate was calculated based on the purchase price minus the remaining value (20\% of the purchase price for the tractor and $37 \%$ of the purchase price for the air-blast sprayer) divided for the economic life of the equipment. The annual interest was calculated on the present value $(50 \%$ of the purchase price for each equipment) multiplied for investment interest rate $(1.5 \%$ for each item). Then to find the fixed hourly costs, the total fixed costs for each equipment were divided into the annual machine use (service life divide to the economic life for the coefficient of use, $75 \%$ for tractor and $100 \%$ for air-blast sprayer). The assessment was performed using technical parameters found in the specialized literature that, for each category of machines, allowed the estimation of the operating cost starting from the new value and the power of the machine. The total variable costs were $32.35 € \mathrm{~h}^{-1}$, divided in $20.18 € \mathrm{~h}^{-1}$ for tractor and $12.17 € \mathrm{~h}^{-1}$ for air-blast sprayer. Instead, the total fixed hourly costs were $10.52 € \mathrm{~h}^{-1}$, divided in $5.79 € \mathrm{~h}^{-1}$ for the tractor and $4.73 € \mathrm{~h}^{-1}$ for the air-blast sprayer. Finally, the total hourly cost was $42.87 € \mathrm{~h}^{-1}$.

The data related to the technical and economic analysis of error pathways have been summarized in Tables 2 and 3 .

During the entire season, the machine has travelled a total distance of $1450.9 \mathrm{~km}$, of which $437.24 \mathrm{~km}$ in the working phase with the sprayer active and $1013.65 \mathrm{~km}$ in the transporting step respectively. The errors related to the erroneous pathways TEP for each AR levels were reported both in kilometres and percentage \% (Table 2). The percentage represents the single path error (RI; NAI; NTI; NEB) divided by total path error of each AR. Moreover, the total TEP $(57.34 \mathrm{~km})$ and the absolute error of RI, NAI, NTI and NEB were highlighted in Table 2. Specifically, $14.46 \mathrm{~km}$ were measured for the RI, $21.72 \mathrm{~km}$ for the NAI, $13.63 \mathrm{~km}$ for the NTI, and $7.53 \mathrm{~km}$ for the NEB. Finally, a sum-

Table 2. Descriptive statistics of the four types of errors: RI monitored repeated inter-rows, NAI non-alternating sprayed inter-rows NTI non travelled inter-row and NEB non-sprayed external boundary.

\begin{tabular}{|c|c|c|c|c|c|c|c|c|c|c|c|c|c|}
\hline \multirow{2}{*}{$\begin{array}{l}\text { Appl. rate } \\
\mathrm{L} \mathrm{ha}^{-1}\end{array}$} & \multicolumn{2}{|c|}{ RI } & \multicolumn{2}{|c|}{ NAI } & \multicolumn{2}{|c|}{ NTI } & \multicolumn{2}{|c|}{ NEB } & \multicolumn{2}{|c|}{ Total } & \multirow{2}{*}{$\begin{array}{l}\text { Mean } \\
\text { km }\end{array}$} & \multirow{2}{*}{$\begin{array}{l}\text { STD } \\
\mathrm{km}\end{array}$} & \multirow[t]{2}{*}{ CV } \\
\hline & km & $\%$ & km & $\%$ & km & $\%$ & $\mathrm{~km}$ & $\%$ & km & $\%$ & & & \\
\hline $\mathrm{AR}_{150}$ & 0.08 & 6.86 & 0.46 & 37.63 & 0.12 & 9.39 & 0.57 & 46.12 & 1.23 & 4.43 & 0.306 & 0.243 & 0.793 \\
\hline $\mathrm{AR}_{200}$ & 2.01 & 16.50 & 6.31 & 51.79 & 2.24 & 18.39 & 1.62 & 13.32 & 12.18 & 7.55 & 3.044 & 2.190 & 0.719 \\
\hline $\mathrm{AR}_{250}$ & 12.37 & 28.16 & 14.95 & 34.03 & 11.27 & 25.65 & 5.34 & 12.16 & 43.94 & 17.69 & 10.984 & 4.065 & 0.370 \\
\hline Total & 14.46 & - & 21.72 & - & 13.63 & - & 7.53 & - & 57.34 & - & - & - & - \\
\hline
\end{tabular}

AR application rate is in $\mathrm{L} \mathrm{ha}^{-1}, \%$ represents the weight of every single error path on the total of them on each level AR, STD is standard deviation and CV represents the coefficient of variation.

Table 3. Costs for fuel, pesticide and water used in the crop protection season.

\begin{tabular}{|c|c|c|c|c|c|c|c|c|}
\hline \multirow{2}{*}{\multicolumn{2}{|c|}{$\begin{array}{l}\text { Application rate } \\
\mathrm{L} \mathrm{ha}^{-1}\end{array}$}} & \multicolumn{2}{|c|}{ Fuel } & \multicolumn{2}{|c|}{ Pesticide } & \multicolumn{2}{|c|}{ Water } & \multirow[t]{2}{*}{$€ \mathrm{~m}^{-1}$} \\
\hline & & $€(+)$ & $€(-)$ & $€(+)$ & $€(-)$ & $€(+)$ & $€(-)$ & \\
\hline \multirow[t]{4}{*}{$\mathrm{AR}_{150}$} & RI & \multirow{4}{*}{$\begin{array}{l}0.22 \\
1.19\end{array}$} & & 1.82 & & \multirow{4}{*}{$\begin{array}{l}0.02 \\
0.09\end{array}$} & & \multirow{2}{*}{0.01} \\
\hline & NAI & & & 9.99 & & & & \\
\hline & NTI & & 0.30 & & 2.49 & & 0.02 & \\
\hline & NEB & & 1.45 & & 12.24 & & 0.11 & 0.01 \\
\hline \multirow[t]{4}{*}{$\mathrm{AR}_{200}$} & RI & \multirow{4}{*}{$\begin{array}{c}4.93 \\
15.48\end{array}$} & & 86.38 & & \multirow{4}{*}{$\begin{array}{l}0.51 \\
1.59\end{array}$} & & 0.03 \\
\hline & NAI & & & 271.14 & & & & \\
\hline & NTI & & 5.50 & & 96.27 & & 0.56 & \\
\hline & NEB & & 3.98 & & 69.74 & & 0.41 & 0.01 \\
\hline \multirow[t]{4}{*}{$\mathrm{AR}_{250}$} & RI & \multirow{4}{*}{$\begin{array}{l}31.61 \\
38.21\end{array}$} & & 391.71 & & \multirow{4}{*}{$\begin{array}{l}4.05 \\
4.89\end{array}$} & & \multirow{2}{*}{0.02} \\
\hline & NAI & & & 473.39 & & & & \\
\hline & NTI & & 28.79 & & 356.75 & & 3.69 & \\
\hline & NEB & & 13.65 & & 169.16 & & 1.75 & 0.01 \\
\hline \multicolumn{2}{|c|}{ Partial $(€)$} & 91.63 & 53.67 & 1234.43 & 706.67 & 11.14 & 6.54 & \\
\hline \multicolumn{2}{|c|}{$\mathrm{FC}_{\mathrm{TEP}}(€)$} & \multicolumn{2}{|c|}{145.30} & & & & & \\
\hline \multicolumn{2}{|c|}{$\mathrm{PC}_{\text {TEP }}(€)$} & & & \multicolumn{2}{|c|}{1941.10} & & & \\
\hline \multicolumn{2}{|c|}{ WCTEP (€) } & & & & & \multicolumn{2}{|c|}{17.69} & \\
\hline
\end{tabular}


mary of descriptive statistics of mean, standard deviation (STD) and coefficient of variation (CV) of the TEP of each AR was done. The costs $(€)$ for fuel, pesticide and water consumption were reported in Table 3. The individual costs were calculated for each level of AR and within each level. Then the costs were divided by the four types of operative error (RI, NAI, NTI, NEB) and expressed as $€(+)$ or in deficit $€(-)$, i.e., costs deriving from meters of inter-row canopy sprayed in excess or shortfall. Totals of the various cost items (FC TEP, PCTEP, $\left.\mathrm{WC}_{\mathrm{TEP}}\right)$, differentiated, for each item, in excess and in deficit costs were reported (Table 3 ). The average daily working session highlighted a time of $9.53 \mathrm{~h}$ divided among working, transport, and idle, with average fuel consumption of $113.27 \mathrm{~L}$. The fuel consumption measurements during work phases were $13.85 \pm 0.05 \mathrm{~L} \mathrm{~h}^{-1}$, while for the transport phases were $7.76 \pm 0.05 \mathrm{~L} \mathrm{~h}^{-1}$. Based on such analyses, the FCTEP total variable fuel costs generated by the incorrect execution of the treatments was $145.30 €$ per season. Of this, $91.63 €$ were due to the RI and NAI in excess of the correct one, while $53.67 €$ were the costs of NTI and NEB that the yard should have performed. The item of total variable costs of pesticides generated by the incorrect execution of the treatments was $1941.10 €$ per year. The costs calculated for the errors RI and NAI attributable to a condition of over-sprayed were $1243.43 €$. The total variable cost items associated with NTI and NEB impact on the annual budget for $706.67 €$. Finally, the water costs of total error path ( $\mathrm{WC}_{\mathrm{TEP}}$ ), generated by the incorrect execution of the treatments, was $17.69 €$ per year, divided in $11.14 €$ attributable to a condition of over-sprayed caused by RI and NAI error paths, and in $6.54 €$ generated by NTI and NEB error paths. The efficiency rates (Max, Min, Mean) of each AR levels and the whole protection stage were reported in Table 4. Efficiency rates highlighted low values on all working days with an average value during the entire season of 0.37 . The minimum efficiency rate was achieved in the AR250 phase and settled to 0.18 . Instead, the maximum efficiency rate is 0.5 and was reached in the AR 250.

\section{Discussion}

\section{Pathways errors}

The analysis of seasonal errors showed that there was independence between the AR phases based. The phases $\mathrm{AR}_{150}$ and $\mathrm{AR}_{200}$ highlighted lower error proportions in the ratio among $\mathrm{km}$ worked with $4.43 \%$ and $7.55 \%$, respectively, compared to $17.69 \%$ of the $\mathrm{AR}_{250}$

Table 4. Mean, maximum and minimum efficiency rate, specified for each AR levels and for the whole protection stage.

\begin{tabular}{lll} 
Application rate $\left(\mathrm{L} \mathrm{ha}^{-1}\right)$ & & Efficiency \\
\multirow{3}{*}{$\mathrm{AR}_{150}$} & Max & 0.37 \\
& Min & 0.23 \\
\multirow{2}{*}{$\mathrm{AR}_{200}$} & Mean & 0.29 \\
& Max & 0.50 \\
& Min & 0.19 \\
$\mathrm{AR}_{250}$ & Mean & 0.37 \\
& Max & 0.50 \\
\multirow{3}{*}{ Whole protection stage } & Min & 0.18 \\
& Mean & 0.38 \\
& Max & 0,50 \\
& Min & 0.18 \\
& Mean & 0.37 \\
\hline
\end{tabular}

phase. If overall length values were considered, the $\mathrm{AR}_{250}$ phase had the largest number of km erroneously travelled (43.94 km). The error distribution among the three AR phases showed a greater uniformity for the phase $\mathrm{AR}_{250}$ with a CV 0.370, while the $\mathrm{AR}_{150}$ phase had the highest $\mathrm{CV}$ of 0.793 , consequent of the limited proportion of the RI and NTI error. The smaller amount of erroneous pathways in $\mathrm{AR}_{150}$ phase may be due to both the overall reduced distance travelled and the greater attention in the execution of the work sessions, which led to fewer errors. This phase represented a strategic time period in the grape growing season. It was characterized by high susceptibility to the risks of infestations due to climatic conditions favourable to the diffusion of pests and disease for which it was necessary to protect the growth of shoots and inflorescences (Siegfried et al., 2016). The pathways
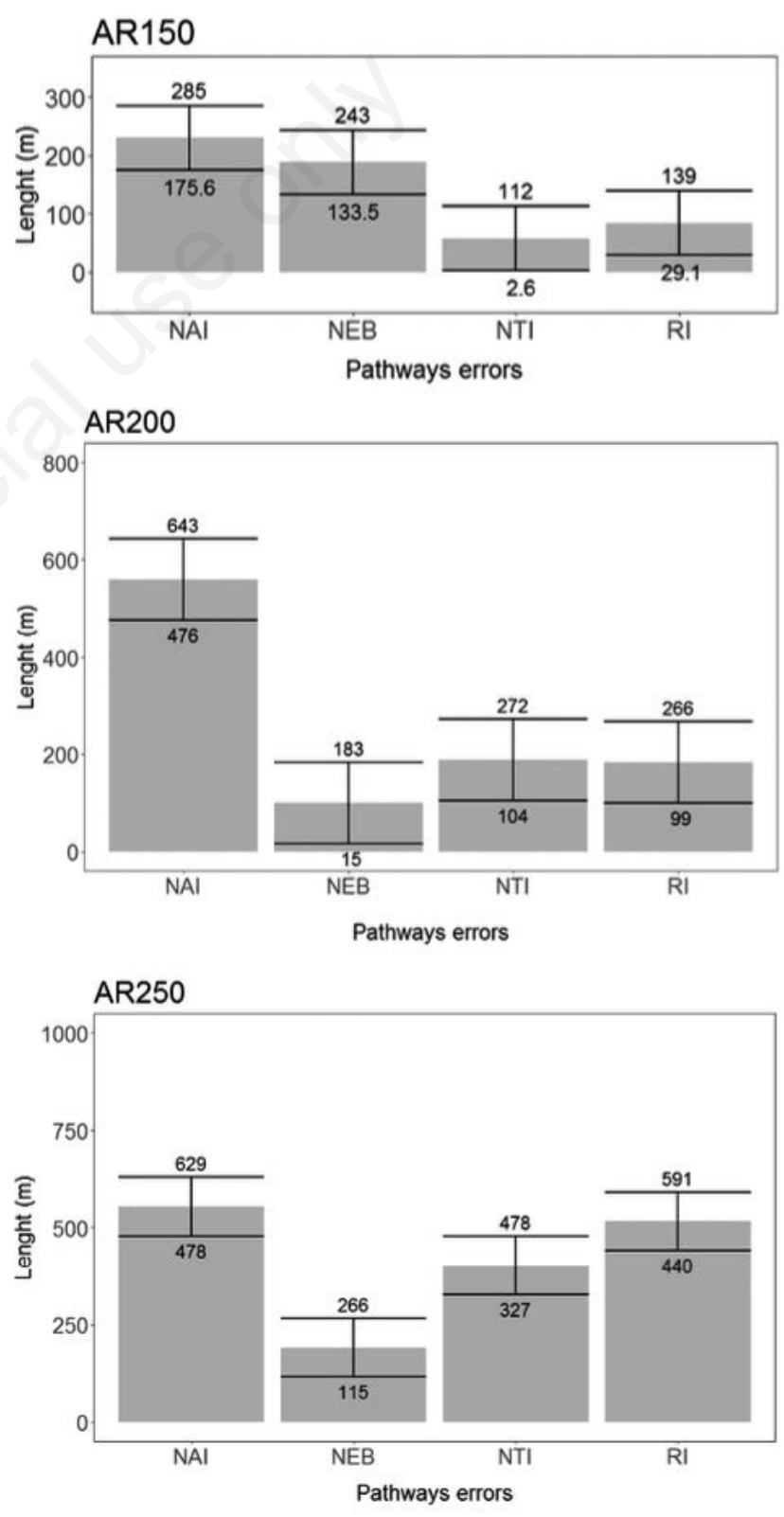

Figure 3. Least squares means and $95 \%$ confidence interval bars of error pathways $(\mathrm{m})$ in the three different application rates. 
errors scenario highlighted both higher absolute and average values $(\mathrm{km})$ across the ARs for the NAI with $21.72 \mathrm{~km}$ on $57.34 \mathrm{~km}$ (Figure 3). In the cases that were identified, the spraying yard travelled two adjacent rows and then continued following the rows alternately. One of the smaller amounts of error NAI in $\%$ $(37.63 \%)$ on three levels, is in the $\mathrm{AR}_{150}$ phase.

In this phase, this result was probably due to vineyard soil management. In fact, in the vineyards cover crops were seeded in alternating inter-rows way. The presence of the cover crops in alternating inter-rows makes the correct inter-rows clearly distinguishable by the passage of mechanical means. This was also confirmed for RI error that, overall, resulted in $\mathrm{AR}_{150}$ the one with the lowest incidence $(6.86 \%)$ in proportion to the $\mathrm{km}$ travelled incorrectly. During the season, the cover crops progressively disappeared due to the natural decomposition process and the field processing carried out (Snapp et al., 2005). Also, the canopy growing makes the operating scenario uniform and the combination of these factors increases for the operator the difficulty of proper inter-rows identification. The maximum detected value of RI $(12.37 \mathrm{~km}$ $28.16 \%$ ) was observed in the $\mathrm{AR}_{250}$ phase, i.e. when the LAI had almost reached its maximum value.

Total pathways errors related to NTI have an important amount $(13.63 \mathrm{~km})$ in relation to the other types of errors. They constitute the type that exposes the production process to higher risks due to the almost complete absence of coverage differently from the NAI in which part of the endo-drift, can induce a partial coverage in those parts of the canopy not reached by the direct spraying. This inefficiency of the distribution process could cause production losses with negative effects on the yield.

Total errors of non-sprayed external boundaries (NEB) represent those with reduced rates of pathways error in terms of kilometers $(7.53 \mathrm{~km})$. Its impact was mainly linked to logistical-operational reasons. In the analysis of the potential causes that induced this error, it has been observed the impossibility to carry out properly turning maneuvers due to the limited spaces at the headlands, which led the operators not to deal the path. This type of error leads to the no spraying of the external boundaries of vineyards, and so it exposes the vineyard to damage risks due to the absence of coverage. This opens the way to diseases inoculation in the vineyard, which may destroy the bunches. These low-efficiency rates were due to the site of vineyards because they were located far enough from each other, so transport times would reach high value lowering the efficiency rate consequently.

\section{Cost analysis associated with pathways errors}

The cost analysis was focused on the consumption of fuel, pesticide and water consumption. The total costs due to path errors were $2104.09 €$, but the incidence of each item on the total was very different. The costs related to fuel consumption in the excess or shortfall have been a limited influence on variable costs. Based on the market price of agricultural fuel, equal to $0.85 € \mathrm{~L}^{-1}$ (CCIAA Siena, 2018), throughout the season there has been extra consumption of $107.80 \mathrm{~L}$, while $63.14 \mathrm{~L}$ for the part of not-consumption. This volume, if compared to the fuel consumption during the work phase, which was $13.85 \mathrm{~L} \mathrm{~h}^{-1}$ with average working productivity of $1.8 \mathrm{ha} \mathrm{h}^{-1}$, was equivalent to an area of 14.01 ha.

Total costs of water consumption have had even less impact on the total variable costs compared to those of the fuel. They have affected the total costs for $17.69 €$. In terms of water consumption, there was a consumption error of $5980.05 \mathrm{~L}$, which corresponds to six full sprayers not correctly sprayed.

The part of the variable costs generated using pesticides was the cost item with the greatest impact (1941.10€). During the sea- son, there was a progressive increase in the average cost of the pesticide mixture due to the intensification of treatments and the introduction of systemic products with a higher unit cost.

The result of cost analysis associated with path errors was a progressive increase in the error cost per linear meter, which varies between $0.01 € \mathrm{~m}^{-1}$ and $0.03 € \mathrm{~m}^{-1}$.

\section{Conclusions}

The study highlighted how the absence of tracking systems in the yards used in the crop protection limited the knowledge of the critical aspects which could emerge after improper spraying execution. From an operational point of view, it was highlighted that in the progress of the vegetative season the presence of devices that can assist workers in driving the spraying yard to limit pathways errors is desirable. The telemetry system allowed the acquisition of useful information for the understanding of the operative dynamics of crop protection stage, allowing an analytical characterization of the management process. The errors detected made it possible to evaluate critical issues in both operative and economic terms. Within the context of growing attention to the sustainable use of pesticides, the telemetry systems have proved to be a valid support for farmers. Despite the wide configurability of the Agroplanning platform, improvements are needed in order to increase the number of parameters to monitor (analogue and digital inputs).

\section{References}

Abeledo M.C., Bruschetti F., Priano D.A., Calbosa D., Crubellier R., Iriso P., Abete E. 2016. Application of wireless technology to determine optimum maturity in strains of Malbec vineyards for Argentine wine sectors. In: CACIDI 2016 - Congreso Aergentino de Ciencias de la Informatica y Desarrollos de Investigacion 7785984. Institute of Electrical and Electronics Engineers Inc., Buenos Aires, Argentina. Available from: http://dx.doi.org/10.1109/CACIDI.2016.7785984

Acquedotto del Fiora. 2018. Tariffe del Servizio Idrico Integrato, a decorrere dal 01/01/2018 (ai sensi della Deliberazione AIT n. 18 del 27/07/2018 e Deliberazione ARERA n. 665/2017 allegato A, art. 3.4 lettera a). Available from: https://www.fiora.it /source/upload/files/tariffe_2018.pdf

ASABE. 2006. EP496.3: Agricultural Machinery Management. In: ASABE Standards. ASABE, St. Joseph, MI, USA.

Camera di Commercio Industria e Artigianato di Siena. 2018. Listino n`30 del 08/08/2018. Available from: https://www.si. camcom.gov.it/uploads/publisher/123-listino-n.30-del-08-082018-.pdf

Castillo-Ruiz F.J., Pérez-Ruiz M., Blanco-Roldán G.L., Gil-Ribes J.A., Agüera J. 2015. Development of a telemetry and yieldmapping system of olive harvester. Sensors (Switzerland) 15:4001-18.

Cima. 2019. Link 55. Available from: https://www.cima.it/atomizzatore-link-55/s7f29762c Last accessed: 26.07.2019.

ESRI. 2013. ArcGIS Desktop: Release 10.3 Environmental Systems Research Institute, Redlands, CA, USA.

Gil E., Arnó J., Llorens J., Sanz R., Llop J., Rosell-Polo J.R., Gallart M., Escolà A. 2014. Advanced technologies for the improvement of spray application techniques in Spanish viticulture: An overview. Sensors (Switzerland) 14:691-708.

Google Earth. 2019. Available from: https:/www.google.it/intl/it/ 
earth/download/gep/agree.html Last accessed: 26.07.2019.

Microsoft. 2013. Microsoft Excel 2013 (15.0.4919.1000) MSO (15.0.4919.1002).

New Holland Agriculture. 2019. Trattori T4 F/N/V. Available from: https://agriculture.newholland.com/eu/it-it/prodotti/ gamme/trattori/t4fnv/informazioni-tecniche

Oksanen T., Linkoletho R., Seilonen I., 2016. Adapting an industrial automation protocol to remote monitoring of mobile agricultural machinery: a combine harvester with IoT. In: IFAC Conference on Sensing, Control and Automation Technologies for Agriculture, AGRICONTROL, Seattle, USA.

R Core Team. 2013. R: A language and environment for statistical computing. R Foundation for Statistical Computing. Vienna, Austria.

Reyes J.F., Correa C., Esquivel W., Ortega R., 2012. Development and field testing of a data acquisition system to assess the quality of spraying in fruit orchards. Comput. Electron. Agric. 84:62-67.

Sarri D., Martelloni L., Vieri M. 2017. Development of a prototype of telemetry system for monitoring the spraying operation in vineyards. Computers and Electronics in Agriculture 142:248-59.

Siegfried W., Viret O., Huber B., Wohlhauser R. 2016. Dosage of plant protection products adapted to leaf area index in viticulture. Crop Protect. 26:73-82.

Sika - PICORE. 2019, Available from: https://www.sikapicore.net/fr/ Last accessed:10.09.2019.

Snapp S.S., Swinton S.M., Labarta R., Mutch D., Black J.R., Leep R., Nyiraneza J., O’Neil K. 2005. Evaluating cover crops for benefits, costs and performance within cropping system niches. Agron. J. 97:322-332.

Tseng C., Jiang J., Lee R., Lu F., Ouyang C., Chen Y., Chang C. 2006. Feasibility study on application of GSM-SMS technology to field data acquisition. Comput. Electron. Agric. 53:45-59. 